tion of each calculated. A general list, including representatives of all the sciences, was also compiled by interpolation, but neither this nor the separate lists are published. An interesting table is given showing the divergences between the ten judges in the case of psychology, as an illustration. The order of merit given by one of the judges is very much more accordan with the average order than those of the others, and they differ considerably inter se, though more, if we understand the table rightly, in the case of those at the bottom of the list than of those towards the top. Of the first hundred scientific men on the list who are eligible, sixty-one are included among the ninety-seven members of the National Academy of Sciences. The discussion of the grades and probable errors is continued in Science for November 30, and in a third and concluding article in the issue for December 7 Prof. Cattell investigates the geographical distribution of American men of science, according to place of birth and place of residence. The figures as regards the former are extremely striking. The production or " birth-rate" of men of science per million of the population ranges from about 109 in Massachusetts-which stands far above the other States-and eighty-seven in Connecticut down to rates of only one or two in several of the southern States. It is argued that differences in stock can scarcely be great enough to account for this, and that accordingly the production of scientific men must be largely a matter of circumstance. As regards the place of residence, interesting tables are given showing the institutions with which the men of science taken into account are connected. The work forms part of an extended investigation which Prof. Cattell has now been conducting for some ten years, and on which he has published several previous memoirs.

\section{WAVE ACTION IN RELATION TO ENGINEERING STRUCTURES.}

A PAPER on wave action in relation to engineering A structures, by Major D. D. Gaillard, issued as a professional paper (No. 3I) of the Corps of Engineers of the United States Army, contains a great deal of information useful to engineers engaged in designing and constructing sea defences and other works subject to wave action.

The first part of the book is devoted to a general consideration of the theory of the formation of waves, and to a notice of the information that already exists as to this. This, as the author remarks, is embraced in so many volumes that the work of comparing theoretical and observed wave characteristics is rendered very tedious. The investigations that have previously been made into wave action, and of which the results have been published, relate principally to deep-water waves, whereas there is very little recorded information as to the action of waves in comparatively still water to which engineering structures are exposed.

Major Gaillard, the author of this book, was for several years engaged upon works of harbour improvement on the South Atlantic coast and the Great Lakes of America.

Although the waves to be dealt with in Lake Superior are not of the magnitude of those in the open sea, yet the author's observations cover waves of various dimensions extending up to 300 feet in length and 23 feet in height, and the results are recorded of several hundred observations of their length, height, period, and depth in which they broke and to which their effect extended. Numerous examples are also given of the effect of waves in moving large masses of stone and other material. The force of the waves breaking on piers, and other marine structures, was measured both by the marine dynamometer of the class used by $\mathrm{Mr}$. Thomas Stevenson more than half a century ago and also by dynamometers of special construction made under the author's directions. The general type of the Stevenson dynamometer used had discs of from 3 inches to 9 inches, with springs varying in strength from io $\mathrm{lb}$. to $50 \mathrm{lb}$. for every inch of elongation. The greatest dynamical force recorded with these when used at Dunbar, in Scotland, was $7840 \mathrm{lb}$. per square foot with waves about 20 feet high. These dynamometers only measure the dynamic, and not the static, pressure, and give only a maximum reading for a storm observation, and are affected in their working when there is much sand in the water.

The instruments invented and used by the author, besides the Stevenson type, consisted, in one case, of a steel plate, having an area of one square foot, attached to two elliptical springs similar to those used for carriages, the distance between their centres being 6 inches, the reading of the amount of compression due to the action of the wave being recorded by a rod attached to an index which acted on a paraffin surface. The instrument, before being fixed, was rated by having weights placed on the plates and noting the corresponding compressions. The other dynamometer used by Major Gaillard consisted of a plate covering a square foot attached to a horizontal cylinder filled with water; over the flange of this cylinder was placed a diaphragm of india-rubber $\frac{1}{4}$-inch in thickness, having a face of one square foot. A $\frac{3}{4}$-inch pipe led from the cylinder to a tank located in the observing station on the pier. From this pipe there was a communication to a modified form of Bourdon gauge fixed I9 feet above the centre of the diaphragm, and which registered pressures up to $30 \mathrm{lb}$. per square inch. Communication with the tank having been shut off, any pressure applied to the diaphragm was transmitted by the confined hydrostatic column to the gauge. More than a thousand readings of wave action were taken with this class of dynamometer while the author was in charge of the works, but only two storms of consequence were encountered. So far as the observations went, the instrument appears to have given satisfactory results.

The text is accompanied by a number of illustrations taken from photographs of waves.

\section{SCIENCE IN EXAMINATIONS FOR THE HIGHER CIVIL SERVICE.}

$T H E$ kind of education received and the subjects studied by future civil servants must have a great and farreaching effect upon the infiuence exerted by the public departments which administer the multitudinous and diverse affairs of our scattered Empire. The methods adopted for the selection of such officers must, therefore, be wisely chosen, and, in any examinations designed to facilitate the process of discrimination between men offering themselves for these positions, the subjects in which candidates are tested must be those appropriately related to the work of the department in which successful candidates will be employed, and, at the same time, those most likely to test essential fitness for public work. These and similar principles have been widely canvassed recently both in public addresses and in the Press. Certain changes in the examinations for the selection of Foreign Office clerks and attachés in the Diplomatic Service are to be introduced, and the new regulations have not met with universal approval. It will assist clearness of thought first to compare briefly the existing regulations for the appointments concerned with those shortly to come into force.

Candidates for clerkships on the establishment of the Foreign Office and for attachéships in the Diplomatic Service will, after July $\mathrm{r}$, instead of being examined according to special regulations which have governed these appointments hitherto, be required to take the combined examination for open competitions for the Home Civil Service (class i.), India Civil Service, and Eastern Cadefships. This decision profoundly modifies the conditions of selection for service in the Foreign Office and the Diplomatic Service. In the past there have been nine obligatory subjects-arithmetic, handwriting and orthography, English composition, précis writing, French, German, general intelligence, geography, and the history of Europe from 1789 to 1880 inclusive. In addition, candidates have been able to offer any two of the following languages, viz., Latin, Italian, Spanish, Portuguese, Russian, modern Greek, and Arabic. In the examination which such candidates will have to take after July I next, papers will be set in thirty-two different subjects, from which a selection must be made by the candidate. French and German will be the only obligatory subjects, and candidates will have to reach a high qualifying standard in translation, composition, and oral examination in both NO. I94I, VOL. 75] 